\title{
The Status of the British Rose Forms as determined by their Cytological Behaviour.
}

KATHLEEN B. BLACKBURN, M.SC.,

AND

J. W. HESLOP HARRISON, D.Sc.,

Armstrong College, Newcastle-on-Tyne.

With Plates IX and $\mathbf{X}$, and five Figures in the Text.

\section{INTRODUCTORY.}

THE study of the genus Rosa was commenced in the year 1913, chiefly 1 with the object of throwing, if possible, some light on one of the most baffling problems presented by the British Flora, that is, the value to be assigned to the various rose forms. This investigation was carried out at first simply from the systematic side, but so hopeless was the task rendered by the extraordinary polymorphism of the plants considered, that quite early it became evident that no real scientific progress could be expected from that standpoint alone. Nevertheless, that very variability provided the clue which we consider destined to establish the true status of the Rosae.

Accustomed as we had been to work with hybrids (both plant and animal) of every degree of complexity, we could not help being impressed by the close analogy between the so-called rose species and our artificial hybrid products. The problem, therefore, shifted from the ground of the systematist to that of the geneticist, and we set ourselves to determine, if possible, the hybrid nature, or otherwise, of the plants we were studying. Two lines of approach seemed capable of yielding the desired solution :-

I. Known hybrids like Rosenberg's Drosera longifolia $\times$ D. votundifolia amongst plants, and our hybrid Bistons and Oporabias amongst animals, when examined cytologically, display characteristic anomalies in their maturation divisions ; do the Rosae exhibit the same behaviour?

[Annals of Botany, Vol. XXXV. No. CXXXVIII. April, 1921.] 
2. Recognized plant hybrids generate ill-developed pollen; is that of the Rosae equally imperfect?

Although the cytological work was begun the earlier, the second research has been published first (Harrison 1920); still, we must point out that a résumé of the cytological results was given in a paper read by one of us at the British Association meeting in August, 1920. Of the latter paper the present account is an expanded statement.

Straightforward as the questions propounded seemed to be at first sight, difficulties were soon encountered, for apomixis occurs in its facultative guise in practically every rose species or microgene. Thus, if the bulk of our roses are hybrids, as the results of both researches indicate, in the Rosae as in other genera, Taraxacum, Erigeron, Hieracium and the like, hybridity, polymorphism, and apomixis are related to each other in the way of cause and effect. The elaboration of this point will be reserved for the discussion at the end of the paper.

\section{Material, Methods, \& $c$.}

All of the material examined, with the exception of that of Rosa arvensis and part of that of $R$. rubiginosa, was collected in Northumberland and Durham and was determined by ourselves. Our determinations we can guarantee to be accurate because the necessary examinations were carried out on the growing bush-a sine qua non when dealing with critical microgenes.

In our earlier work the young buds were fixed in Flemming's fluid, but later other fixatives were tested, to be abandoned finally in favour of Carnoy's fluid, which, for the end in view, proved the best reagent.

The sections were cut to a thickness of $5 \mu$, stained with Heidenhain's iron-alum-haematoxylin, and mounted in balsam without a counterstain.

Very early indeed we became aware that in the genus microspore formation occurred of two types, one perfectly normal and the other exhibiting irregularities, varying with the microgene under investigation, but nevertheless always of the same order. Furthermore, it appeared that the abnormalities occurred in forms with high chromosome numbers, but were almost absent in those with lower complements, i. e. in microgenes with a haploid number of 7 or 14. Incidentally, it will be evident that Strasburger was in error in fixing the fundamental chromosome number in Rosa as 8 , the correct figure being 7 .

The most frequent form examined with this latter haploid number was one of the Systylae, Rosa arvensis, and upon that species, aided by reference to $R$. pimpinellifolia, we shall found the description of events in the meiotic phase of a normal rose to be utilized subsequently in comparisons with anomalous forms. 


\section{The Meiotic Phase in the Species Behaving NORMally.}

(a) Rosa arvensis, Huds.

As this is not intended to be a critical survey of the cytology of Rosa, but is rather an inquiry into the status of its British members, the series of sections figured here simply displays representative stages in pollenformation, sufficiently complete in themselves to show that in the truly sexual roses the general course of events differ not at all from that followed in typical phanerogams.

The stages chosen for figuring commence with Pl. IX, Fig. I, in which we depict the resting nucleus just preparing for synapsis by an increase in the bulk of its chromatin. Onward from this there is a progressive massing of the chromatin to one side of the nucleus, where it is arranged, more or less neatly, between the nucleolus and the wall. When synapsis is at its maximum intensity, the chromatic clump becomes exceedingly dense and granular, as is shown in Pl. IX, Fig. 2. As the synaptic knot unravels, obviously looped sections are thrown out into the nucleus (PI. IX, Fig. 3). Next the loops extend until the whole nuclear cavity is filled, and the ordinary hollow spireme stage is reached. The beaded spireme then thickens, and, as it does so, reveals itself as made up of seven long loops. The succeeding stage shows the units of the bivalents twisted round each other (Pl. IX, Fig. 7). Henceforth the chromosomes concentrate and thicken with an accompanying increase of their staining powers and a diminution in the case of the nucleolus to more or less cytoplasmic values (Pl. IX, Fig. IO). Subsequent to this an irregular multipolar spindle (Pl. IX, Fig. II) of a transient nature arises, passing by imperceptible steps into the typical bipolar form. At this point the somewhat oval chromosomes reach the spindle (Pl. IX, Figs. 12 and I3) when, as is quite plain, they lie with perfect regularity on the equatorial plate; now, too, the nucleolus has disappeared. The separation of the bivalents takes place with the utmost regularity, and the chromosomes, without exception, reach the poles simultaneously (Pl. IX, Fig. I4).

No hint is given here of hybridity; the perfect assembling of the chromosomes on the equatorial plate, their synchronizing in doing so, the neat arrangement of the separated chromosomes on the spindle, as they pass to the poles, force upon one's mind the certainty that, in this species at least, no hybridity exist either patent or latent. There is absolutely no suggestion of lack of pairing, irregularity in passing to and from the equatorial plate, so obvious in the heterotype division of Drosera obovata, or of the first maturation division of our Lycia-Nyssia and Oporabia moth hybrids.

In P1. IX, Fig. I 5 the interkinesis between the heterotype and the homotype divisions may be seen with the chromosomes represented so that no longer can the chromosome number be made out. At this stage the nucleolus comes once more into view. 
The homotype divisions succeeding this call for no special remark, so ${ }^{\circ}$ great are their uniformity and fidelity to type. Perhaps we should state that the two spindles, for the most part, as shown in Pl. IX, Fig. I8, lie at right angles to one another.

As the chromosomes reach the poles they are grouped together, but immediately separate, becoming granular and once again uncountable in the process (Pl. IX, Fig. I9). Once more, too, the nucleolus becomes an evident adjunct of the nucleus. Finally, and with but little delay, the mother-cell divides into four spores, which with the secretion of a cell wall bring into being a perfectly ordinary tetrad and, later, functional pollen (Pl. IX, Fig. 20).

Ordinarily a brief account of the course of events in the meiotic phase of a plant, such as we set out to give, would be complete at this point. However, in view of the extraordinary discrepancy between the somatic and semi-reduced chromosome number in the majority of roses on the one hand, and of the regular haploid and diploid relationship in those of Rosa arvensis and the average phanerogam on the other, the facts must be emphasized by figures of a somatic mitosis in that rose.

Pl. IX, Fig. 2 I shows a somatic nucleus in late prophase, exhibiting very clearly the splitting in preparation for the ensuing division, whilst Fig. 22 shows a typical equatorial plate. In both, without the faintest possibility of equivocation, the somatic number is I4. In other words, the haploid number for Rosa arvensis is 7 and its diploid 14 , these numbers bearing the normal relation to each other.

\section{(b) Rosa rugosa, Thun.}

Rosa rugosa, an occasional escape or covert shrub in this district, displays essentially similar features to those described for $R$. arvensis, its diploid number likewise being $I_{4}$ and its haploid 7 . Only one fact seems worthy of special mention in connexion with this rose, and that is the very considerable quantity of granular chromatin matter present in the nucleus during diakinesis. Otherwise it is very ordinary in its behaviour. Under these circumstances, to avoid unnecessary duplication, we do not supply a series of figures for it, but content ourselves by inserting a good example of a homotype anaphase (Pl. IX, Fig. I7) to illustrate its perfect regularity at a stage when most rose forms exhibit their worst behaviour.

\section{(c) Rosa pimpinellifolia, L.}

With this form we include the hispid glandular peduncled $R$. spinosissima as well as a tall sterile bush indistinguishable otherwise than in its stature and sterility from $R$. pimpinellifolia. All three forms, in contrast to the irregular tetraploid Villosae, appear, save in one slight detail in the sterile type, as wholly normal tetraploids. 
Cytologically speaking, they deviate but slightly from the path followed in Rosa arvensis, but to emphasize their great approximation in this respect and their total disagreement from all other British roses some account must be given.

As in $R$. arvensis, the granular chromatin of the resting nucleus of the pollen mother-cell masses itself into a dense synaptic knot, which persists as such for some fairly lengthy period whilst the mother-cells are separating. In the end loops are thrown outward to the periphery of the nucleus; after this the knot gradually unloosens to build up the apparently continuous spireme (PI. IX, Fig. 4). Presently this thread thickens and shortens to be seen as being made up of loops divided lengthwise either completely or sectionally, thereby evolving the twisted hairpins of Pl. IX, Figs. 5 and 6. To the interpretation of this split we shall revert under Rosa Sabini. These bivalent loops, the halves of which at first are so attenuated as to be barely visible, rapidly condense to yield the V's, X's, and O's of a typical diakinesis (Figs. 8 and 9).

The 14 bivalent chromosomes then approach one another with the accompanying development of a multipolar spindle. This, however, speedily gives place to the bipolar variety, and the chromosomes take their places on the equatorial plate. This event occurs in the usual fashion in fertile pimpinellifolia and in the spinosissima segregate; on the contrary in the sterile plant ${ }^{1}$ one chromosome may be detected as a fifteenth one lying in the region of one of the poles (Text-fig. I). In all instances, except for the larger chromosome number, the further stages are exactly

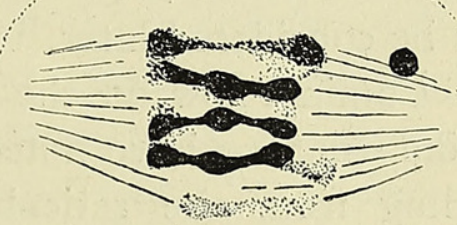

TeXT-FIG. I. R. pimpinellifolia. Heterotype metaphase showing odd chromosome like body. $\times 3,000$. parallel to those of Rosa arvensis and R. rugosa.

The somatic count may be made out to be 28 in the trio of forms, although some small amount of difficulty may arise in the process, owing to the length and curvature of the chromosomes (PI. IX, Fig. 23). That the haploid number is I4, Fig. 22 amply demonstrates.

\section{The Cytology of the Phenhybids of Rosa.}

(a) Rosa Sabini $(=R$. pimpinellifolia $\times R$. tomentosa var. sylvestris).

The plant about to be considered belongs to that heterogeneous assemblage known to the early rhodologists as Rosa involuta, Smith. Now, of course, it is universally deemed to be a hybrid between Rosa pimpinelli-

1 These tall plants are always sterile in Durham, and this slight abnormality, their tallness and sterility, may all be relics of some crossing in the previous history of the form. 
folia and a member of the Villosae, using the sectional name in its widest sense as covering the Rosa mollis, R. omissa, R. tomentosa, and R. foetida groups.

After careful study in the field of the bush whence our preparations were derived, and making due allowance for its neighbours, we have decided that its exact parentage is $R$. pimpinellifolia $\times R$. sylvestris-seemingly quite a frequent combination in our two counties; as confirmatory proof of its hybrid nature, if any were needed, we may say that, wherever we have come into contact with it, it has been uniformly barren-a point neglected by most previous writers, who have merely observed its wealth of blossom in June and July.

Recognizing the importance of determining the somatic chromosome number correctly in order to procure confirmation of our diagnosis of the parentage, careful counts were made from clear prophases in the styles where, as is general in the genus, such figures are very frequent. Such counts prove difficult to make accurately, owing to the unusually large number of chromosomes present and their elongated shape. Nevertheless, in favourable nuclei, the number has been ascertained with complete exactitude to be 42 (Text-fig. 2, $a$ ). The precise significance of this number will be considered later.

Coming now to the behaviour of the chromosomes during meiosis, unlike what we have noted in moth hybrids of the genus Lycia, the stages leading from the reticulum onward through synapsis seem absolutely normal. Pl. X, Fig. 26, showing the synaptic knot at its greatest contraction, differs in no wise from the same stage depicted for Rosa arvensis on Pl. IX, Fig. 2, and is quite representative of the number examined. By degrees the open spireme stage is attained in which the thread, in spite of its delicacy, can be followed in its continuity with some amount of ease as it winds around the periphery and elsewhere in the nucleus (see Pl. X, Fig. 27). With the passing of this stage, certain of its threads are seen to lie parallel, thus initiating the formation of the bivalents. Here we must remark that it would appear a fair deduction, when one allows for the future development of bivalents and univalents pari passu, to assert that the chromatic thread as it emerges from synapsis is still univalent; one cannot conceive of its being univalent and bivalent at one and the same time. This should be set against the parasyndetic appearance of the stage of $R$. pimpinellifolia depicted on Pl. IX, Figs. 5-7, as it seems unlikely that the species should differ in this respect.

Gradually the chromosomes thicken and concentrate, and very early indeed it becomes evident that whilst certain individuals are, without any possible doubt, bivalent, others just as assuredly remain unpaired and can often enough be detected as marvellously straight single rods. Concentration proceeds regularly in bivalent and univalent alike until in 
diakinesis (figured on P1. X, Fig. 29) both types are determinable with the greatest possible ease.

Compared with similar stages in other plants, subsequent events follow an anomalous course, which, however, in the light of extensive studies in Rosa, is found to be more or less characteristic of the genus. In assembling on the equatorial plate for the heterotype division, the 14 bivalents mass themselves round the central point of the spindle with the utmost regularity. Later the univalents follow with less exactness and arrange themselves in a complete ring round the paired individuals (Text-fig. 2, b). In good sections showing horizontal plates, the total number of chromosomes is 28 , which agrees perfectly with the somatic count of 42 , since I4 bivalents + I4 univalents yield a total of 42 .

The anaphase, too, is noteworthy, for it occurs in two distinct phases, one involving the bivalents and the later one the univalents. Often enough the former is almost over (Pl. X, Fig. 33), and even sometimes merging into the telophase, before the univalents split and attempt to move. It would almost appear that the force urging the chromosomes had spent itself with the passage of the bivalents, since the split halves of the remainder lag, wander, and occasionally get lost. However, in the majority of cases, the greater portion of the split halves unite in the telophase with the I4 whole chromosomes already awaiting them, to constitute one daughter nucleus. Still a few of the laggards mass themselves apart into groups of varying size, and finally develop into micronuclei (see Pl. X, Fig. 34). An interesting feature in connexion with the heterotype spindle, in this form, is its close proximity to the periphery of the mother-cell, as is well shown on Pl. X, Fig. 34 .

Very soon after the short interkinetic period preparation is made for the homotype division. The fact that many of the split halves of the univalents are included in the two major nuclei becomes very apparent here, for counts on good homotype plates (P1. X, Fig. 38), differing widely in number it is true, but often reaching the twenties, can be made. Once again events move abnormally. As before, the chromosomes descended from the original I4 bivalents travel first to the centre of the plate followed by a varying number of halves. The former divide precociously and pass to the telophase with such rapidity that before many of the splitting halvès can approach them the daughter nuclei may be reconstructed. Thus there is a general tendency for the major nuclei, representing the genuine nuclei of the tetrad, to be built up from i4 chromosomes. Curiously enough, the dividing halves derived from the univalents seen in the original diakinesis may also show a more or less pronounced inclination to keep together, although they may diverge. When they do act as a unit, the 'tetrad' contains eight major nuclei and may therefore more appropriately be termed an 'octad'. On the other hand, if they separate, when 
due allowance is made for the micronuclei developed after the heterotype division, large numbers may be present.

However, whether the number of microspores is great or small, their fate is already sealed, for they all collapse.

In view of the great theoretical importance attached to the fact an occurrence observed during the hybrid homotype division must be mentioned. In one pollen mother-cell, instead of the usual pair one giant spindle had been formed involving the whole of the split univalents and the bivalents. Thus in the late anaphase the huge array of chromosomes could be seen lying in two orderly groups, just as if the cell were pursuing a normal mitosis (see Pl. X, Fig. 40). Had development been allowed to proceed, resulting in a functional pollen grain, we should have had a gamete possessing all the necessary qualifications for producing a new plant, orthoploid in its chromosome number, but with a complement much higher than those of the plants from which it was generated. Further reference will be made to this phenomenon later.

Finally, on account of its extreme importance, we must insist that the meiotic plan just traced is that displayed by a plant admitted by every rose student in England to be of hybrid origin.

\section{(b) Rosa hybrid pimpinellifolia $\times$ (pimpinellifolia $\times$ coriifolia).}

Of the hybrid nature of this form no doubt can be entertained, and on grounds detailed at length in the concluding remarks we have determined that its parents are as stated above.

As with the plant just considered, to fix its parentage and to enable us to comprehend fully the nature of the chromosomes to be accounted for in the meiotic stages, careful counts of the number of chromosomes occurring in the nuclei of the cells of the style were made. The numbers so obtained seemed to vary slightly even when the accuracy seemed guaranteed, so that whilst in most cells 28 chromosomes were to be made out (Text-fig. $2, c$ ), in others 29 appeared to be present.

When seen in polar view the plates of the heterotype division (Text-fig. 2 ,d) gave without exception counts of 14 , indicating that, in all probability, there were on the plate, as in the type previously studied, 14 pairs of bivalents. However, views of the spindle in profile during the anaphase demonstrated that widely separated chromatin fragments, and even possibly the halves of split univalents (Pl. X, Fig. 35), lay along the spindle fibres.

Thus the interkinesis before the homotype divisions held in store few untypical features likely to end in abnormalities during the division, thereby ensuring that reasonable numbers of perfect microspores should result. This was reflected for the most part in the appearance of a regular tetrad of four nuclei. Rarely, however, five or six could be observed. Moreover, too, the condition of the pollen varied with the loculus, some loculi containing 
up to 100 per cent. of good grains, whereas in others the percentage was much lower. Frequently the pollen did not mature at all.

Making the requisite allowance for the much smaller chromosome complement, the whole of the stages examined showed no significant deviation from what obtained in the preceding type.

(c) Rosa coriifolia var. Lintoni $\times R$. lutetiana.

For reasons put forward in the concluding remarks (p. 177) we have decided that the parentage of the plant about to come under consideration is what we have just stated, and a further critical study of its neighbours made recently has sufficed to confirm our opinion.

Buds were collected from the plant at exactly the same time as we made our gatherings of Rosa omissa, $R$. rubiginosa var. apricorum, $R$. coriifolia var. Lintoni, $R$. dumetorum var. hemitricha, and $R$. lutetiana. After fixing the buds of the whole lot for the same length of time in portions of the same stock of Carnoy's fluid they were cut, stained, and mounted. For some unknown reason, whilst the first four took the stain readily, we had the utmost difficulty in overcoming the capricious behaviour of this rose and $R$. lutetiana towards iron-haematoxylin. Even at its best it never took this stain like the
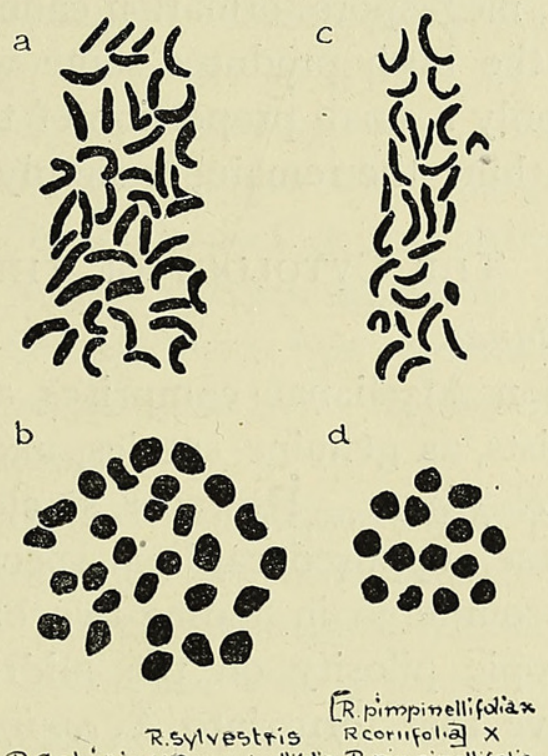

R.Sabini $=X$ R.pimpinellifolia R.pimpinellifolia

TEXT-FIG. 2. Somatic and heterotype metaphases in hybrids. $\times 3,000$. rest of the roses we have mounted.

Basing our opinion upon a number of prophases of which Text-fig. 2, $e$, is quite typical, we have no hesitation in fixing its somatic chromosome number at 35 , and we are convinced that seven of these were obtained from the lutetiana parent and twenty-eight from the other. There would thus be brought in from the latter twenty-one, which are presumably unaccustomed to act as homologues of others in the stages leading to the semitypical reduction division, and seven that were descended from chromosomes capable of doing so. From Rosa lutetiana came in seven of like character to the latter group. Naturally one would expect that the last two sets would be homologous to one another and be paired in the imperfect reduction division.

In Text-fig. $2, f$, the seven bivalents may readily be discerned lying in 
a horseshoe shape with some of the univalents included within its arms, although most are arranged so as to surround them partially. Both at earlier stages and subsequently matters move in the very strange fashion described at some length for $R$. coriifolia and, save that the bivalents in this case are seven in number, for $R$. Sabini.

In the interkinesis we see two major nuclei, with varying numbers of micronuclei as well as with odd degenerating chromosomes. In the homotype the movement of the chromosomes to the spindle is even more disturbed by the hybrid combination at work, and despite the fact that the scheme followed is that typical of pentaploid forms, the tetrad is so very abnormal that almost the whole of the microspores are abortive. Two per cent. of good grains was the best count made from a microscopical inspection of the contents of a number of anthers.

Similarly, megaspore formation cannot have been uniformly successful, for, although the bush produces some well-developed seeds by a process of apomixis, only a small proportion of the fruits swell satisfactorily as the seeds ripen within; the remainder simply contain a mass of chaffy scales.

\section{The Cytology of the Pentaploid Group.}

(a) The Afzelianae.

The section Afzelianae comprises all of the segregates classified by English botanists, as genuine species, under the old collective names Rosa coriifolia and $R$. glauca. However, so closely do the forms assigned to one or other of these supposed cardinal species approach one another, that no difficulty is encountered in finding two bushes absolutely identical, save for some microscopic pilosity on the midribs of the leaflets of one, which suffices to drive that form into $R$. coriifolia and the other into $R$. glauca. From this the recognition of the two seems ridiculous, and to avoid their unnatural separation Almqvist united them under the oldest collective name capable of covering both sets of plants; that name was Rosa Afzeliana. At the same time, he removes the glandular microgenes, considered by most workers on the genus Rosa to be true segregates of $R$. coriifolia, to the section Rubiginosae. In this, whilst we recognize some sound reasons for the procedure, we are unable to follow him; the gradual transition from $R$. coriifolia (type) to $R$. Lintoni renders it almost impossible to differentiate virescent forms near the type from the less glandular varieties of the roses so transferred. Thus, our conception of the Afzelianeae differs from what Almqvist includes under the name, inasmuch as, in our opinion, the section contains the whole of the old 'species' $R$. coriifolia and $R$. glauca.

(I) R. coriifolia, Fries.

This plant was almost the first to which we turned our attention. We were very fortunate in our choice. In it we secured almost ideal material 
for disclosing the peculiarities characterizing the meiotic phase in Rosa. Examination of its somatic mitosis very soon brought us into contact with the unorthodox chromosome number of thirty-five. Although influenced, no doubt, by the apparent certainty of Strasburger's count of thirty-two in other roses, and likewise by the improbability of the occurrence of pentaploid species, we were inclined to think that our counts were rendered unduly high by the presence of precociously dividing chromosomes, by their being cut accidentally by the microtome or split by other means. However, the somatic number is urdoubtedly thirty-five, and Text-fig. $3, a$, adequately represents the large number of somatic prophases from which we have made counts.

In the meiotic stages, when direct comparisons are made with $R$. arvensis and $R$. pimpinellifolia at parallel points, whether preceding, during, or just subsequent to synapsis, no discrepancies are to be noted. There is the same gradual passage from the reticulum to close synapsis yielding in its turn to an equally perfect hollow spireme. Notwithstanding this close resemblance here, in the later stages they disagree in almost every detail, and to determine the exact import of the striking differences manifested the outline of events during meiosis described for $R$. Sabini must be carefully borne in mind. Coupled with this reference to $R$. Sabini must be the fact that this rose is admitted to be of hybrid origin by every one competent to put forward an opinion.

Returning now to $R$. coriifolia, after the formation of the loops from the spireme in the heterotype prophases, we have, as with $R$. arvensis, a thickening and condensation of the chromosomes, which, however, are seen to be behaving dissimilarly. Some are clearly discernible as threads folding and interlacing on themselves, as the sides of the individual loops close up; others are just as certainly isolated portions, severed, so to speak, from the contracting spireme. In this fashion, we glean that the plan followed adheres rather to that of $R$. Sabini than to that of $R$. arvensis. Further, the view is strengthened in diakinesis, for the chromosomes in sight are very obviously pårtly bivalents and partly univalents. Nevertheless, although the bivalent combinations are decidedly in the minority, no perfect count can be made of the precise number of each type present, for the total number of chromosomes is too great.

As the chromosomes pass to the spindle all this uncertainty passes away. In a regular manner, observed in one heterotype metaphase after another, the bivalents arrange themselves with mathematical precision immediately around the centre of the equatorial plate (see PI. X, Fig. 30), and in doing so reveal themselves as being seven in number (see Text-fig. $3, f)$. Next, the univalents approach and encircle them, in general with considerable regularity, giving beautifully clear plates, on which twenty-eight chromosomes lie visible, the seven inner bivalents standing out as larger 
and blacker than the remainder. First the bivalents separate in their anaphase, actually reaching the poles ere their companions divide (see Pl. X, Fig. 36).

When the latter do so we have an anaphase totally distinct and much less in accord with type. With extraordinary fidelity the events recorded for $R$. Sabini are reproduced. Nor does the resemblance end here; just as related for that plant, the attraction (or repulsion?) urging the chromosomes to the poles seems to lose its strength long before the whole of the split univalents reach their goal. Some of the failures wander and degenerate, whilst others join company in little groups of three and four, to appear later in interkinesis, as micronuclei, comparable with those recorded long ago for the same stage in Hemerocallis fulva by Strasburger and Juel. That the majority do manage to reach the seven separated bivalents in the 'polar cap' is demonstrated in a convincing fashion in the homotype division, for there, once again, the plates, ideal in their simplicity, show numbers varying from sixteen to twenty-five. Once more the seven whole chromosomes, derived from the former associated pairs, travel to the plate first and arrange themselves centrally, with somewhat less precision, to be enclosed later by the chromosomes representing the split halves of the heterotype phase. An equatorial division then takes place for the first set, when their halves travel rapidly towards the poles (see Pl. X, Fig. 39). Although delayed in the end the others divide, but rarely, if ever, pass more than two-thirds of the way up the spindle fibres. As the outcome of this premature halting the major daughter nuclei contain almost uniformly seven chromosomes, that number having been determined in scores of cases. Nor is there any great difficulty in making out the same number, when the chromosomes display themselves with much less sharpness of outline, in the major nuclei of the final octad.

To go back to the fate of the delayed number; with some regularity, much greater than in the analogous case of $R$. Sabini, they tend to crowd together, thus entailing, with the reconstruction of the daughter nuclei, the development of eight major groups. From this we learn that usually, as already stated, an octad rather than a tetrad is generated; still, however, we must bear in mind that the term, although allowable in the circumstances, is not strictly correct, when due cognizance is taken of the number of micronuclei likewise included (see Pl. X, Fig. 4I). Be that as it may we have, arising from the pollen mother-cell and lying somewhat carefully spaced within the octad, eight nuclei, markedly different from the rest. These, acting independently, take unto themselves separate portions of cytoplasm, secrete the normal exine, and finally yield pollen grains. The fate of the micronuclei varies. If entrapped within the sphere of influence of one of their larger comrades they are included within the microspore to which it gives rise. On the other hand, one, two, three, or even more 
acting together may take part of the cytoplasm to themselves, to develop in the end into pollen grains of dimensions varying with the chromatin content of the nuclei, whence they originate.

After this, in the bulk of the pollen grains, degeneration sets in, although a fair proportion, as proved by direct observation, are quite functional.

Giving due weight to the exceedingly close resemblance between the whole of the events during microspore formation in $R$. coriifolia and $R$. Sabini, from the typical preparatory stages to the anomalous later ones, and recollecting the perfectly ordinary and orderly meiotic phase in $R$. arvensis, we are forced to the opinion that the same agency, hybridity, is responsible in the first-named pair of plants for their common peculiarities. Undoubtedly, the very least one can say is that the cytological behaviour of $R$. coriifoliz is that of a hybrid.

(2) Rosi coriifolia var. Lintoni, Scheutz.

This rose is one of the glandular members of the Afzelianae and would, by Almqvist, be regarded as appertaining to the Rubiginosae. We prefer, for reasons perfectly apparent when the rose is studied as it grows, to leave the rose as placed by English rose students.

Its somatic chromosome number, as in the case of the type, adds up to thirty-five. Further, as far as the chromosomes are concerned, we cannot perceive any divergence of behaviour between the two. As in Rosa coriifolia, Fr. they appear in the heterotype division as seven bivalents and twenty-one univalents, and the descendants of these are distributed in the final microspores in the same general fashion.

One important point of difference is manifested; without exception, during synapsis and the stages intervening between that and diakinesis, the nucleolus appears to be doublcd. Often enough, there are actually two nucleoli present; less frequently they assume an exact dumb-bell shape, whilst most commonly we have the appearance of a minor nucleolus attached to a greater. Whether this is to be interpreted as a vigorous budding of the nucleolus during the most critical period of the existence of the nucleus we know not, but we are not inclined to admit that explanation.

In any case, the exact significance of the phenomenon, and why the two allied forms should so consistently differ in this respect, we cannot state.

(3) The Rosa glauca group.

Rosa glauca will not delay us long. Just as in the other groups more than one microgene was examined, and these were Rosa Reuteri, God. (uniserrate), $R$. venosa, Schwartz, R. subcristata, Baker (biserrate), and $R$. stephanocarpa, Dés. and Rip. (biserrate and with subfoliar glands). 


\section{I72 Blackburn and Harrison.-The Status of the British}

Once more we discovered that we were dealing with "members of the pentaploid group with a somatic chromosome complement of thirty-five, as Text-fig. $3, b$, from $R$. Reuteri will suffice to show.

Except for one single point, that we fancied the synaptic knot to be tighter than in the allied $R$. coriifolia, the cytology of the two Afzeliana types, completely coincides. Text-fig. $3, g$, from $R$. stephanocarpa will prove that this is the case as far as the arrangement of the chromosomes is concerned. There the seven bivalents can be made.out surrounded by
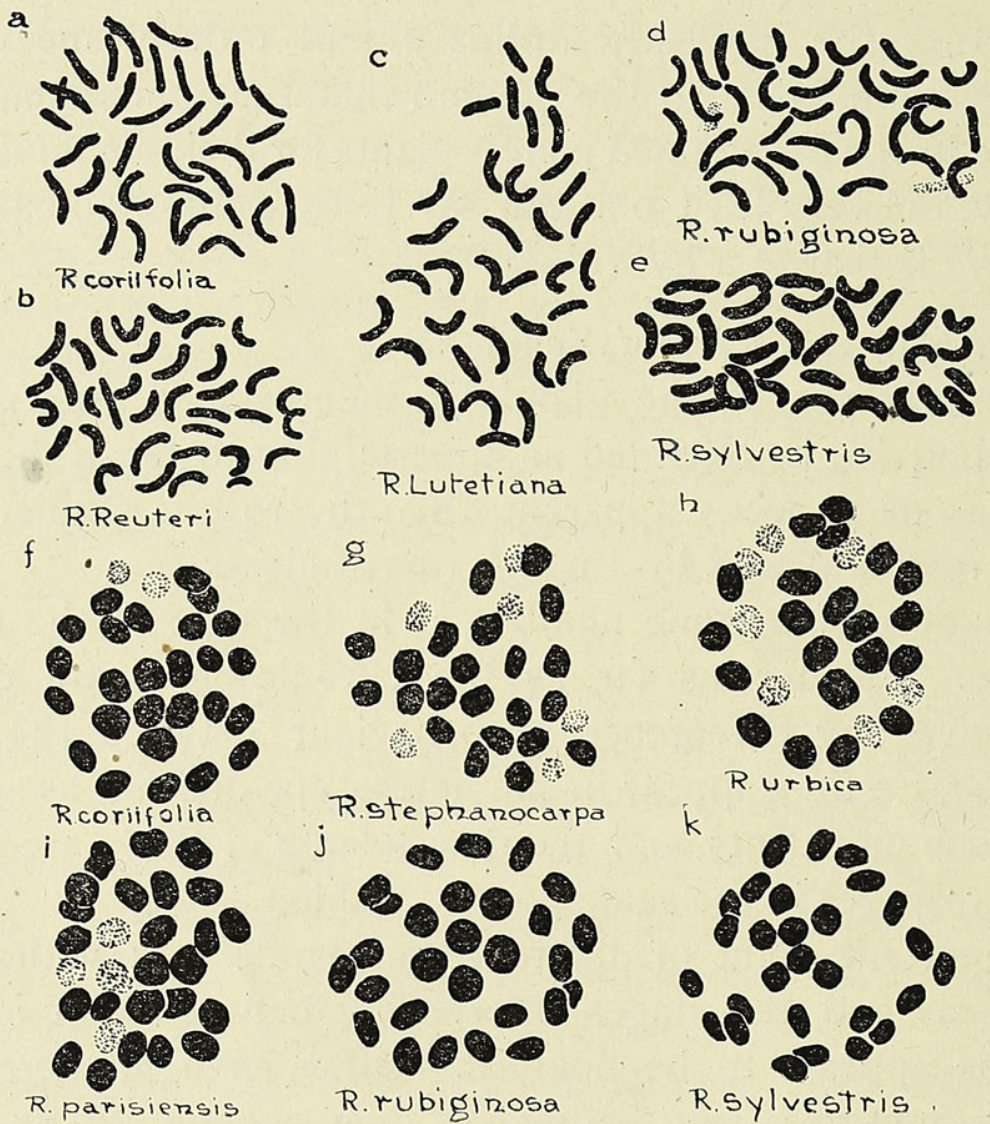

R.sylvestris
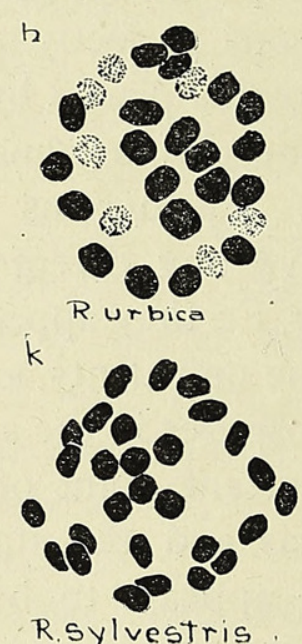

TEXT-FIG. 3. The pentaploid roses. Somatic and heterotype equatorial plates. $\quad \times 3,000$.

the complementary univalents. Giving due weight to their agreement, no additional treatment seems necessary.

(b) The Eucaninae.

To us the term 'Eucaninae' covers all the 'ultra'-microspecies ranged in Wolley-Dod's list under the canina and dumetorum groups; it thus appears as an aggregate systematically, if not genetically, equivalent to a collective species.

We regard $R$. dumetorum, once deemed a very important macrospecies, as quite an unimportant entity when placed alongside its associates.

Notwithstanding this, to indicate precisely what forms we have studied, we give their names as set down in the list to which we have 
just referred, and likewise keep the hairy-leaved forms separated from their glabrous allies.

(I) Rosa canina, Linn.

The segregates brought under examination were $R$. flexibilis, Déség., $R$. fallens, Déség., $R$. separabilis, Désés., and $R$. parisiensis, Rouy, the first three forms being uniserrate and the other biserrate.

Without exception all possessed a chromosome count of thirty-five in the nuclei of the somatic cells (Text-fig. $3, c$, from $R$. lutetiana) and were therefore pentaploid.

As with $R$. coriifolia, these chromosomes were of two types, as revealed during meiosis, fourteen being bivalents and twenty-one univalents (see Pl. X, Fig. 28). Text-fig. 3, $i$, represents a heterotype plate from the pollen mother-cell of $R$. parisiensis, and, as in $R$. coriifolia, the bivalents are arranged centrally with the univalents round them. Whilst generally the phenomena displayed during the stages immediately preceding the heterotype division and the distribution of the chromosomes during the division itself very closely resemble that visible in $R$. coriifolia (and therefore not requiring a full description), there is a more emphatic raggedness on both heterotype and homotype spindles, with regard to the univalents. This involves a greater abundance of micronuclei in the interkinesis between the maturation divisions, and a consequent accentuation of this number in the subsequent 'octad'.

However, as the seven chromosomes of the 'cap' seem never to be affected, this would appear, in some way, to be an advantage, for the functional pollen grains are bound to be much more generally endowed with that chromosome combination. In these plants, up to 50 per cent. of good pollen in the anther is not an unusual occurrence (see Pl. X, Fig. 44). This, in its turn, explains why, compared with the Afzelianae, the Eucaninae are more often fertilized and less prone therefore to apomixis.

(2) Rosa dumetorum, Thuill.

Rosa urbica, Lem., a uniserrate form, and R. hemitricha, Rip., a biserrate rose, yielded our material. Both microgenes are pentaploid. Once more the complement of thirty-five comprises fourteen destined to play the part of bivalents in the reduction division and twenty-one that of univalents, as the heterotype plate on Text-fig. $3, h$, will show for $R$. urbica.

In every detail the description of events given for the canina and coriifolia segregates, with the qualifications mentioned under the former, apply here; to repeat them would thus be superfluous. Still, one fact should be noted; in the hemitricha form a much greater tendency seems to be manifested for the micronuclei to collaborate with their bigger companions in the development of the tetrad, so that multinucleate microspores are not uncommon. Also, necessarily, the concomitant of this 


\section{I74 Blackburn and Harrison.- The Status of the British}

is aborted pollen and a lack of intensity of the orange colour, when contrasted with that of pollen of a superior grade, seen in the other canina and dumetorum segregates. At its very best $R$. hemitricha has only produced I 5 per cent. of perfect pollen in its anthers.

As in the Afzelianae, so in the Eucaniae, we regard the abnormalities in cytology as pointing directly to hybridity.

(c) The Rubiginosae.

Curiously enough, considered in conjunction with our matured conclusions that nearly the whole of the roses are hybrids, the statement of Boitard in $8_{3} 6$ that many well-known rose growers had obtained seedlings of Rosa ferox from R. nubiginosa seems very illuminating. However, our experiments showed emphatically that $R$. rubiginosa var. comosa, Rip., was facultatively and generally apomictical, so that seedlings from the same plant always agreed amongst themselves and with their parent in characteristics.

This section is not well represented in this district, so that only two microgenes, $R$. comosa and $R$. apricorum, Rip., were studied, our local material of the forms being supplemented by some from Bedfordshire.

In harmony with the Afzelianae and Eucaninae, the Rubiginosae proved members of the pentaploid series, having a somatic chromosome number of thirty-five reducing to twenty-eight for the heterotype division (see Textfig. $3, d$ and $j$ ). That they mass themselves on the equatorial plate as in the other sections will easily be perceived from the same figure, and also from that on Pl. X, Fig. 3I, depicting a heterotype metaphase in profile.

Of the forms previously under review the Rubiginosae most nearly approach $R$. hemitricha, so small is the proportion of pollen capable of germination developed. If the conditions in that plant be borne in mind, coupled with what prevailed in $R$. coriifolia, a good notion will be gained of the meiotic phase in the Rubiginosae ; thus unprofitable repetition will be avoided (see also P1. X, Fig. 42).

One occurrence must be singled out for special reference. In animal hybrids tripolar spindles in the maturation divisions are quite common, whilst in plants, on the contrary, although a tendency to multipolar spindles is the rule, they always yield to the bipolar type ; in $R$. apricorum tripolar spindles occur freely, and, what is more, persist, thus forming one of the factors in the wholesale failure of pollen in these microgenes (see Pl. X, Fig. 32).

This, again, is one of the many features driving home and emphasizing the hybrid origin of practically every British rose.

(d) The Tomentosae.

Since Rosa Sherardi, Dav., has been transferred to the Villosae, the section Tomentosae, as studied by us, is represented by two forms, $R$. sylvestris, Woods, and R. scabriuscula, Sm. 
In their somatic chromosome numbers both are in perfect agreement with the Afzelianae and Eucaninae, and are thus pentaploid. The meiotic features, particularly in $R$. sylvestris, are more atypical than in any form as yet described. The early stages up to diakinesis agree likewise with the pentaploids, but on the initiation of the heterotype spindle marked divergences become apparent. Owing to this increased disturbance, or rather as one of the causes thereof, the difference in behaviour between the bivalents and univalents is much less noticeable. Indeed, it often appears as if many of the chromosomes never reach the equator of the spindle at all, but begin to divide wherever they encounter a spindle fibre. The type of spindle shown more nearly approaches that of Rosa Sabini at the same stage, although, as in that rose, an excellent polar view of the metaphase is occasionally obtained (Text-fig. $3, k$ ). However, the untidy appearance of the assembling chromosomes in R. Sabini depends almost certainly on the
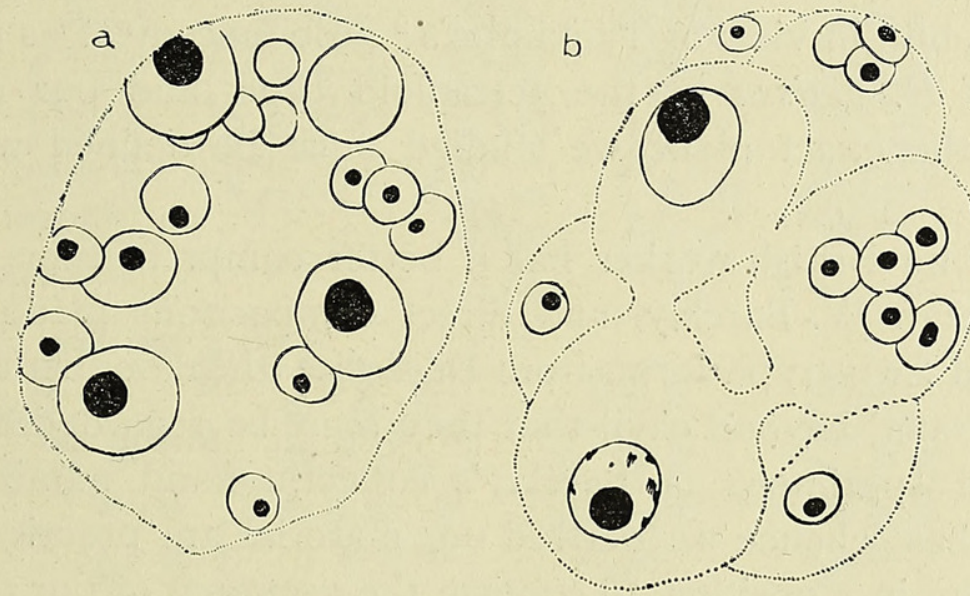

TeXt-FIG. 4. R. sylvestris. 'Octad' before and after division. $\times 3,000$.

difference in size and shape of the chromosomes contributed by the parents, and, moreover, the usual double anaphase ensues in its entirety. On the other hand, there is no period of demarcation between the successive anaphases in the heterotype division of $R$. sylvestris. The chromosomes behave very curiously and seem to lose their shapes and are pulled out into strings and irregular masses. Notwithstanding this, it is in every way probable that all of the bivalent daughter chromosomes, accompanied by a few of the others, reach the poles. The laggards become surrounded by nuclear walls, forming karyomere-like structures, even before the disappearance of the spindle. Hence, in interkinesis, two larger nuclei, as well as a great number of smaller ones, are visible.

The homotype division is so irregular that it is difficult to distinguish the positions of the main spindles. Almost certainly minor spindles interfere with the major ones. As a consequence, what ought to have been the tetrad contains numerous nuclei of varying size. Text-fig. $4, a$, is not at 
all an extreme example of this, and $b$ shows the division into the usual octad in which almost all of the pollen grains are multinucleate (see also Pl. X, Fig. 43).

This accentuated irregularity would seem to suggest that some of the tomentosa forms may be very recent, nay even $\mathrm{F}_{1}$, crosses. Pl. X, Fig. 45 illustrates the regularity of the somatic mitosis even here.

\section{The Cytology of the Tetraploid Types.}

\section{The Villosae.}

This type, as far as the British roses go, comprises within its limits nothing but Villosa segregates, and amongst those prepared for study were representatives of the Rosa mollis group ( $R$. mollis, Sm., and $R$. coevilea, Woods) as well as of the $R$. omissa ${ }^{1}$ group (R.omissa, Déség., $R$. suberecta, Ley., and R. Sherardi, Dav.).

In the case of four of these no further indications of the plant intended are necessary, but, in view of Täckholm's ${ }^{2}$ pronouncement as to the unconformability of $R$. omissa to the tetraploid type, and our proof that it is tetraploid, the exact plant we studied must be defined with complete accuracy.

Probably no British worker has a better comprehension of $R$. omissa than the veteran W. Barclay, and direct comparisons made between his gatherings and Swiss type-forms from Déséglise (the describer of the species) have demonstrated beyond cavil that they must be regarded as conspecific. We possessed specimens of Barclay's collecting and naming, and with these the bushes whence we derived our material are practically identical. Further, we are in a position to confirm the accuracy of our determination indirectly. As Almqvist, the well-known Swedish rhodologist who named Täckholm's plants, needed British roses for examination in order to fix the range of the forms of his new system (and not because we doubted our own namings), we sent him a score of Northumberland and Durham examples with three of Barclay's; all, without exception, were returned as Rosa mollitrachyphylla, Almq. This confirms our belief that Barclay and ourselves were dealing with the same plant and also, as we already knew, that our omissa was a Villosa rather than the Tomentosa form it had been assumed to be. What Almqvist and therefore Täckholm understand by Rosa omissa will appear as a sequel in our concluding remarks and thus reveal the reason for Täckholm's curious findings.

The meiotic phase in these forms is uniform for all, and allowing for its harmony with the same period in $R$. Sabini and $R$. coriifolia one brief description will suffice. It is ushered in by a typical synapsis, opening out

1 Also known sometimes as the $R$. Sherardi or even the $R$. subglobosa group.

2 This paragraph and the next were inserted after we had received a copy of Täckholm's brief paper. 
later in the ordinary fashion into an apparently continuous spireme. When this breaks up its units soon reveal themselves as of two distinct types: univalent rods and twisted bivalent loops. This peculiarity was first observed in Rosa omissa, and afforded the clue which led to the discovery of the partial reduction in pentaploid and tetraploid alike (Pl. X, Fig. 28 a). At the inception of the spindle the bivalents are sharply marked off from the univalents by their early passage to the equator, and even by separating ere the latter reach it. Here we think it necessary to remark that, in spite of this, equatorial plates with all the chromosomes practically in one plane are much more frequent in tetraploid than in pentaploid roses.

The bivalents diverge to the poles first and form a kind of cap, whilst the others divide and keep together in twos and three to pass slowly towards them. In the Villosae nearly all, and indeed sometimes actually all, attain

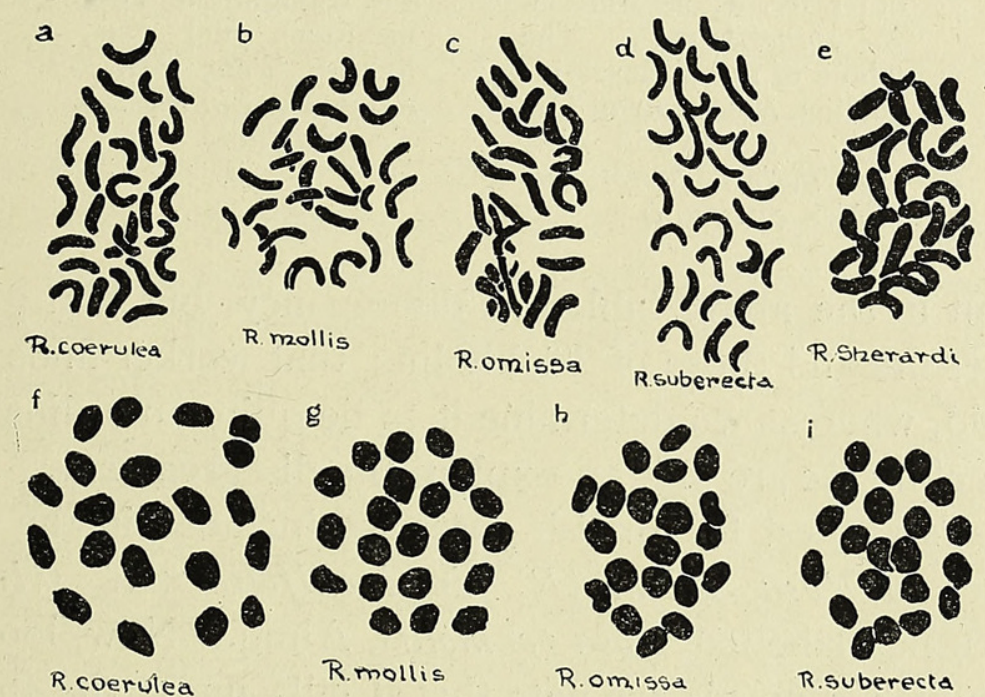

Text-Fig. 5. Section Villosae. Somatic and heterotype metaphases. $\times 3,000$.

that goal, and are included in the daughter nuclei; occasionally one or two may be left out and yield micronuclei.

The homotype divisions begin in much the same way as the heterotype. Usually, however, only the seven descendants of the bivalents group themselves at the poles, for the others delay their splitting so long that they fail to join them, thereby necessitating the formation of accessory nuclei. If this section manage to keep together, the extra nuclei may have as many chromosomes as, or even more than the normal nuclei formed at the cap, but this occurs only rarely. In general we are inclined to think that nearly always they contain less, and only microspores derived from the cap are capable of growth. The cytoplasm of the multinucleate body (better described as an octad) then segments more or less evenly into eight parts, each containing one or more nuclei.

As demanded by the chromosome counts made during meiosis, every Villosa microgene gave a somatic count of twenty-eight (Text-fig. $5, a-e$ ), 


\section{I78 Blackburn and Harrison.--The Status of the British}

and is therefore tetraploid. To all intents and purposes their behaviour agrees with that of the pentaploids and with that of Rosa Sabini, although in this case only seven bivalents appear with the fourteen univalents (Text-fig. $5, f-i$ ).

\section{Concluding Remarks.}

From the foregoing account it appears that in our roses the chromosome number upon which the various complements seem to hinge is seven, and, using this as a base, our local forms arrange themselves as in the appended table :

Diploid.

Rosa arvensis

(Systylae)

Rosa rugosa

(Semiherbaceae)
Tetraploid.

Rosa pimpinellifolia (two forms, one sterile and the other fertile, as well as $R$. spinosissima). The whole of the Villosae including Rosa omissa, Déségl. Rosa hybrid pimpinellifolia $\times$ (pimpinellifolia $\times$ coriifolia $)$.

\section{Pentaploid.}

All the members of the Eucaninae, Afzelianae, Rubiginosae, Tomentosae, and one hybrid, Rosa coriifolia var. Lintoni $x$ Rosa hitetiana.

\section{Hexaploid.}

Hybrid Rosa pimpinellifolia $\times R$. tomentosa var. sylvestris.

As set out in the above table one discrepancy, but that glaring, exists between our results and those of Täckholm; that worker finds Rosa omissa to be hexaploid, whereas we determine it to be quite an ordinary tetraploid Villosan. Luckily we are able to explain the disagreement. When satisfying Almqvist's request for British roses we included in the consignment three examples of Rosa Sabini ( $R$. pimpinellifolia $\times R$. sylvestris). All three were returned labelled Rosa permollis, Almq. Now, looking up this name in Almqvist's synopsis, we note that it falls under the species type of Rosa Acharii and in the section Villosae glauciformes, i. e. with glaucous hairy leaves. Ignoring for a moment that our rose is, without the shadow of a doubt, a pimpinellifolia hybrid, this is demonstrably incorrect, although one cannot blame Almqvist for the error. We sent him specimens with the half-open flowers proper to an involuta form, so that its tomentosa affinities were masked. Judging from its prickle characters alone he was almost compelled to recognize in it a Villosan. Making the necessary correction for the section, we find that under Almqvist's classification it runs out to Rosa omissa, Almq., and thus, as proved from authentic specimens, not of Déséglise. ${ }^{1}$

Almqvist's plant is therefore a pimpinellifolia-tomentosa hybrid parallel to, if not identical with, our Rosa Sabini-a determination explaining the perfect agreement in hexaploidy, and the possession of twenty-eight potential bivalents and fourteen univalent chromosomes, existing between our R. Sabini and Täckholm's R. omissa.

1 This paragraph was added after Täckhoim's paper came to hand. 
Proceeding, let us submit the contents of the table to detailed analysis. The occurrence of diploid, tetraploid, and hexaploid species within the same genus would, at first sight, call for little comment, for intensive work like that of Tahara on Chrysanthemum has revealed in that genus comparable numbers based on 9, Chrysanthemum carinatum having 9 haploid, $C$. leucanthemum 18, C. morifolium 27, C. Decaisneanum 36, chromosomes and so on. On the contrary the pentaploid microgenes, comprising fully ninety per cent. of our roses, are quite unexpected, and in view of the very obvious difficulties in the way of their producing a regular haploid number equivalent to half the diploid, their presence and chromosome complement must be regarded as quite anomalous. Nevertheless, a critical study of their microspore development affords some clue to their evolution. However, deviations from the normal do not end with pentaploid roses; when the contents of the column labelled tetraploid are viewed in the light of the above descriptions they present themselves as a very heterogeneous assemblage. There not only do we encounter forms in which the course of pollen formation is quite as even as in Rosa arvensis upon which we found our comparisons, but in addition microgenes, appertaining to the Villosae, are included with their cytology in complete harmony with that of the pentaploid roses. For the purposes of this discussion the Villosae may thus be considered with the other subsections of the Caninae, i. e. the Eucaninae, Afzelianae, and the like. Similarly, the hybrid between pimpinellifolia and coriifolia may be classed with the hexaploid hybrid. Furthermore, although the chromosomes behaving more or less regularly are twenty-eight in the last two plants, and fourteen in the pentaploid species and the Villosae, both groups may be treated as making one whole, since no significant discrepancies exist between the two sets ; whatever explains the untypical meiotic phenomena of the one explains it in the other.

We are now in a position to take a comprehensive view of the cytological features emerging from our work. Almost immediately we discover that our local roses conform to two types. Type I, including very few species, pursues a course perfectly normal in all its details. Differing therefore in no wise from other phanerogams at the same stage it requires no further treatment than the above. On the other hand, Type II, comprising the vast majority of our roses, whilst offering differences in detail in its various members, follows the same general but untypical plan throughout. In it we have displayed a heterotype division, equatorial as far as the bulk of its chromosomes is concerned, but reductional with a further fixed proportion, generally fourteen, but sometimes twenty-eight in number.

As is obvious, three recognized hybrids are arranged under Type II, and, as far as behaviour goes, they cannot be severed from their companions. The pairing of their homologous chromosomes in preparation for the heterotype division, and the number doing so successfully, are too suggestive 
for that. But in all of their irregular behaviour at this stage-the failure of complete pairing, the lagging of chromosomes both in passing to and from the equatorial plate, the formation of micronuclei, the accentuation of these features in the homotype division, and, finally, the generation of defective pollen-the known rose hybrids differ in no way from what we have pictured for us by Rosenberg as occurring in his Droserae, Tischler in his Bryoniae, and by ourselves, amongst others, in animal hybrids. We must, therefore, assign the same irregular processes encountered at the same stages in Rosa to the same cause, and that cause hybridity. Once having admitted this in the case of the patent rose hybrids, to the same disturbing influence we must look for our explanation of precisely the same unusual occurrences in the other forms; they are assuredly latent hybrids. In this manner, at one stroke, by invoking hybridity we account for the extraordinary phenomenon of pentaploid species, the harmony between their cytology and that of the tetraploid Villosae, and lastly, the whole chain of circumstances arising from the peculiarities in their meiosis.

Digby, following Juel, has urged that all of the above-mentioned irregularities, beginning with the untidy spindle figures and culminating with abnormalities of chromatin distribution in the heterotype and the homotype divisions, cannot be regarded as conclusive proofs of hybridity, and instances the classic case of Hemerocallis fulva as proving that such behaviour occurs in pure species. To us this seems to savour strongly of begging the question, for not a vestige of proof has ever been adduced to substantiate the claims of Hemerocallis, and other plants exhibiting similar divergences from typical microspore formation, to be regarded as 'pure breeds'. On the contrary, if we might be permitted to base our opinions on the definite proofs provided by absolutely the same phenomena detected by Rosenberg in artificial hybrids in Hieracium and by ourselves in the patent crosses in Rosa, and furthermore by aiding our judgement by evidence derived from other instructive similarities, we feel sure that in the case of the plant treated as the crucial example we have a persistent, if more or less latent, hybrid like our roses.

Comparing the pseudo-reduction in the pentaploid roses and their tetraploid associates, and backing up the comparison with what obtains in Rosa Sabini, we are bound to admit that only one satisfactory explanation exists for their common peculiarities. Just as the ten chromosomes derived from Drosera rotundifolia find mates in the reduction division of $D$. obovata in ten provided by the $D$. longifolia parent, so one must conclude that the common seven running through the whole Caninae supersection has been introduced by some species (quite possibly Rosa arvensis) possessing that number as its haploid complement, when it has crossed with a microgene or microgenes with a haploid number of twenty-one in the Villosae and twenty-eight in the rest of the Caninae. This notion might seem to demand 
as a corollary the existence of sexual hexaploid and octoploid roses, if not now, then in some past epoch favouring hybridity.

To postulate sexual forms with such high chromosome numbers would thus seem almost unavoidable were it not that two lines of escape remain open, one in the possible occurrence of repeated back crosses, and the other in mitotic curiosities like the ' mass' homotype (Pl. X, Fig. 40) observed in Rosa Sabini.

In this fundamental hybridity itself lies one source of the variability of the Rosae, since in an ordinary $F_{1}$ generation of species hybrids quite a wide spread of variation between the conditions of the parents is possible. But in the Rosae the spread in any given form (species?) is far beyond that, and hints at that seen in $F_{2}$ generations. We have thus to determine whether any mechanism revealed in the above investigations allows for an approximation to the circumstances of such an $\mathrm{F}_{2}$ lot.

In all the descriptions we have given we have emphasized the constancy of the appearance of seven pairs of chromosomes in the diakinesis, and of a curious duplication of the subsequent anaphase; the anaphase involving this paired lot occurred long before that in which the remainder took part. So long was the latter delayed that, in many cases, the chromosomes never reached the poles, but either formed micronuclei or were lost in the cytoplasm to degenerate there. On the other hand, the associated seven uniformly massed themselves as a cap at the poles, and accompanied by some of the split univalents formed one of the independent major nuclei visible in the interkinesis. At the homotype division these circumstances are repeated and exaggerated, with the result that when functional pollen is formed, in the great majority of cases, the nuclei of the active grains contain only seven chromosomes, and these seven originating in the seven bivalents of the heterotype division. This was beautifully shown in the large number of counts made during a close study of the fate of these chromosomes in Rosa coriifolia (type of Fries).

Since it is merely a matter of chance which member of the original homologous fourteen lies on any given side of the equatorial plate, it appears from this that we have the same mechanism set before us for the segregation of the multitudinous factors of Rosa as is used in explaining the segregation of single Mendelizing factors. With seven chromosomes taking part, the number of possible combinations is enormous, so that gametes carrying them must produce in derived zygotes a huge range of genotypes which we see expressed phenotypically in the excessive variation of the roses.

In order that the constancy in the somatic chromosome numbers may be maintained the egg-cell in the Villosae must be endowed with twentyone chromosomes and in the rest of the Caninae with twenty-eight, exactly as Täckholm has found and as we deduced theoretically. In other words, 


\section{I82 Blackburn and Harrison.-The Status of the British}

when both are functional, the two gametes, the generative nucleus of the pollen grain and egg-cell of the same plant, carry widely different chromosome numbers. Therefore reciprocal crosses between bushes of diverse chromosome complements should result in hybrids with different somatic counts, but when between members of the same group, as in the pentaploid section, they should agree and both be pentaploid. In the only bush of the latter type examined the somatic number was thirty-five as demanded by theory. Moreover, as the bush grew adjacent to and resembled Ros $\alpha$ coriifolia var. Lintoni, it was a fair inference that that microgene had been the seed parent. In addition, since the other roses growing near by were all Rosa lutetiana, and in certain of its characters and ontogeny that form was approximated, Rosa lutetiana in all probability had acted as pollen parent. Now the egg-cell of Rosa coriifolia var. Lintoni would contain a nucleus with twenty-eight chromosomes, and the generative nucleus of lutetiana pollen would probably possess seven, so that if these numbers have any value in determining the affinities of the hybrid it should resemble Lintoni more closely. Such was indeed the case, the lutetiana influence appearing mainly in the styles, stigmas, sepals, and young shoots, and less markedly in the prickles and glandular vestiture.

Similarly, in the case of the Rosa Sabini, if Rosa sylvestris were the seed parent, then the hybrid should possess $14+28(=42)$ chromosomes ; if, on the other hand, it were the pollen parent, the hybrid number ought to be $14+7=2 \mathrm{I}$. Its somatic number was 42 , whence we deduce that almost certainly the first conjecture was true, as was confirmed, firstly, by the fact that the bush in question grows in hedges amongst Rosa sylvestris and far from the nearest Rosa pimpinellifolia, and, secondly, it resembles Rosa sylvestris very much more closely than it does $R$. pimpinellifolia.

The case of the Rosa hybrid pimpinellifolia $\times$ (pimpinellifolia $\times$ coriifolia) is much more difficult to explain. If Rosa pimpinellifolia were the seed parent, as seems likely from the fact that the hybrid grows in a pimpinellifolia colony on the Northumberland sand dunes, and fully Ioo yards from the nearest coriifolia, the chromosome number should be $\mathrm{I} 4+7=21$; if the reverse held true, it ought to be $28+14=42$. Neither figure is correct, the somatic count being 28 .

Now an egg-cell of $R$. pimpinellifolia with fourteen chromosomes must form the starting-point, if we judge from the habitat of the plant. Suppose this to be fertilized by Rosa coriifolia pollen with a nucleus endowed with seven chromosomes. The hybrid would thus display $\mathrm{I} 4+7=2 \mathrm{I}$. In its megaspore formation, should events follow the usual course of Rosa hybrids, seven chromosomes would be shed, leaving an egg-cell with fourteen. As it is a matter of chance how the chromosomes are arranged in the partial reduction division, this fourteen would originate partly with coriifolia and partly with pimpinellifolia. Now for the pollination of this 
rose to take place, situated as it would be amidst an abundance of $R$. pimpinellifolia, other than by the agency of that rose appears a very remote contingency. Thus an egg-cell nucleus with fourteen chromosomes would fuse with that of a pollen grain with fourteen, giving us a zygote with $\mathrm{I} 4+\mathrm{I} 4(=28)$ such as we have.

In this manner, our hybrid reveals itself as a back cross between $R$. pimpinellifolia and a hybrid pimpinellifolia $\times$ coriifolia. Strangely enough it betrays its hybrid nature in the same characters as the coriifolialutetiana cross, i. e. in styles, stigmas, sepals, and prickles.

From this we gather that the chances are great that reciprocal rose crosses should differ as stated above, and that they should be preponderatingly matroclinous.

As we have demonstrated experimentally (Harrison, 1920), certain of the Villosae, Afzelianae, Rubiginosae, and Agrestes set seed by some process of apomixis. Moreover, we have likewise proved this to be of the facultative order, since seedlings showing hybrid characters have originated from flowers, pollinated with foreign pollen, growing on the same bush as those castrated, and producing seeds apomictically. Despite this, in the sections just named, our experiments lead us to the opinion that in their case apomixis is the rule and sexual reproduction the exception. On the contrary, with the lutetiana and dumetorum allies, as well as with certain Villosae, our work indicates with some certainty that, whilst they are too facultatively apomictical, they favour pollination-a view not incompatible with occasional apomixis, as the work of Pace has proved. However, in any case, the difference is merely one of degree, and the situation is best summed up by stating that except for Rosa arvensis, R. rugosa, and R. pimpinellifolia all the roses brought under examination exhibit apomixis.

This must not be assumed to be simple parthenogenesis, because, as we have explained, the egg-cell in the Villosae has only twenty-one chromosomes and in the rest of the supersection Caninae twenty-eight. Should these cells develop without fertilization the somatic numbers in the embryos thus generated must necessarily be twenty-one and twenty-eight respectively, which is emphatically not the case. Judging from the uniform chromosome number of twenty-eight in the Villosae and of thirtyfive in the Afzelianae, \&c., we must conclude that, whatever cell produces the new organism, it must be somatic in origin and therefore possess the chromosome number proper to such cells.

Now let us assemble our facts. We have decided that, whilst the sexual roses are genetically pure, the non-sexual (or occasionally sexual) microgenes are hybrid in nature. Apparently, therefore, some intimate connexion exists" between hybridity and apomixis. Many authors following Rosenberg and Strasburger have seen in the mere size of the chromosome numbers in plants like the Alchemillae and Antennariae a cause of apogamy, 
and others, represented by Gates, by a refined extension of the crude notion put forward by previous writers have been inclined to see in tetraploidy and octoploidy the inciting cause. With neither of these do we agree. We see in our particular form of vegetative reproduction, and in the true apogamy of other species, a further manifestation of the powers of heterosis stimulating, in the one case cells from the soma, and in the other the germ-cells, to an enormously exaggerated development ending in apomictical reproduction. High chromosome numbers are in this view merely the attendant circumstances of the hybridity and the stimulus induced by it.

It needs only a glance to perceive the close analogy between the cytology of roses and that of other forms betraying apogamy or some kindred form of reproduction. Our roses behave exactly like Rosenberg's Hieracia, Holmgren's Eupatoria, and Ernst's Chara crinita. In all of these cases, as in others, the apogamy is assigned to hybridity, and we feel sure that these authors are justified in the position assumed. To our minds apogamy and the enormous variability in Rosa and other critical genera like Hieracium, Taraxacum, Antennaria, and Callitriche alike take their origin from one and the same cause, hybridity-not set in motion now, but in the far distant past.

Whatever value we assign to the various rose forms, and this, in spite of their hybrid nature, cannot be assessed at less than the microgene or Jordanian species, their development became possible through crossing. Moreover, despite the vast range of variation, the centre round which any given microgene oscillates remains fixed; no one, for instance, could ever mistake a member of the Rosa lutetiana fraternity for a $R$. glauca form and so on. Undoubtedly, therefore, hybridity has given rise to these recognizable, if variable, units just as to the more stable Evigeron anmuns, so that hybridity must be admitted as one of the prime factors in the evolution of species, if not the sole one as Lotsy would fain persuade us.

Further, if, for example, we can imagine the egg-cell of Rosa Borreri to be fertilized by a pollen grain built up from the seven 'cap' chromosomes of $R$. omissa, or any other similar cross pollination, it appears far from impossible that some form of microgene building is still proceeding. If apomictical, as seems likely when one remembers the Lord Penzance hybrid Rubiginosae, the new form would be reasonably permanent from the very first. We feel certain that the forms arranged under Rosa subcanina, R. subcollina, and other groups are comparatively recent developments rendered possible by the northern forms belonging to the Afzelianae clashing with the more southern Eucaninae, possibly at the onset of the Glacial Period, whilst others, like $R$. foetida and $R$. andegavensis allies, may even yet be coming into being.

Lastly, we propose to consider the taxonomic value of our observations. 
Since our conceptions of the status of the British roses, derived from the work outlined above and otherwise, differ profoundly from those held up to the present by most, but certainly not all, rose specialists, the ground is not prepared for any definite utilization of the observed chromosome numbers. Notwithstanding this one cannot help being struck by the fact that all of the supersection Caninae, minus the Villosae, are pentaploid forms, which confirms an alliance between the more widely separated $R$. tomentosa and $R$. foetida groups on the one hand, and the Eucaninae on the other, suggested by many similarities more apparent on the growing bushes. In much the same manner the agreement in tetraploidy between the obviously related $R$. mollis, R. omissa, and $R$. Sherardi forms serves to strengthen the case for our previous removal of the whole of these groups to the Villosae. Hence we see that the old classification of $R$. omissa and $R$. Sherardi as tomentosa segregates, upon no more secure basis than the non-persistence of their sepals, fails both when judged from a cytological standpoint and from their undoubted approximation in general characteristics when one examines them otherwise than as dried fragments.

\section{SUMMARY.}

I. The fundamental chromosome number in Rosa is seven.

2. Among the roses examined were diploid, tetraploid, pentaploid, and hexaploid forms.

3. No diploid form was found to be abnormal during meiosis; nor was any member of the pimpinellifolia section among the tetraploid.

4. The remainder of the tetraploids, the whole of the pentaploids and hexaploids, showed a partial reduction involving fourteen or twenty-eight chromosomes.

5. In these partially reduced forms the heterotype anaphase occurred in two steps, one involving the chromosomes to which we have just referred, and the second, and later, taking place when the univalents split.

6. In many cases these split univalents failed to reach the poles and formed supernumerary micronuclei in the interkinesis between the heterotype and homotype divisions.

7. The features mentioned in 5 and 6 are exaggerated in the homotype division, so that, for the most part, the major nuclei in the tetrad are endowed with seven chromosomes in the pentaploids and abnormal tetraploids.

8. When the remainder of the chromosomes keep in two groups, eight major nuclei may arise, thus yielding an octad rather than a tetrad.

9. Multinucleate pollen grains are quite common in the anomalous forms of the genus Rosa, but when these are derived chiefly from micronuclei the pollen grains collapse. 
I0. Known hybrids showed the same type of behaviour as outlined in paragraphs 4-9.

I I. Arguing from points 4-10 we have decided that every rose studied showing partial reduction was really of hybrid origin.

I2 All the abnormal roses are facultatively apomictical; this we assign to the stimulus of heterozygosis.

I3. Hybridity, in this view, is likewise responsible for the wide range of variation in the genus Rosa.

I4. We have shown that hybridity is one of the sources of microgene building in the genus Rosa.

I5. This process of microgene building is probably still proceeding.

I6. Since the functional pollen grains in the supersection Caninae contain seven chromosomes and the egg-cell twenty-one in the Villosae, and twenty-eight in the rest of the Caninae, it is clear that reciprocal hybrids between the two named will have different chromosome numbers.

17. Crosses within the limits of the pentaploid and abnormal tetraploid forms will have the same number of chromosomes as their parents, but, as in the crosses referred to in 16 , will be strongly matroclinous.

\section{LITERATURE CITED.}

AlmQ̨ist, S. : Sveriges Rosae. Stockholm, I9I9.

: Rosae Musei regni suecici in methodum naturalem redactae. Arkiv för Bot., Bd. xvi, No. 9, 1920.

Barclay, W. : Perthshire Roses. Trans. Perth. Soc. Nat. Sci., vol. v, Part II, I 9 Io.

: Our Native Hybrid Roses. Ibid., Pt. III, I9I I.

Boitard, M.: Manuel des Roses. Parig, 1836.

Digby, L. : The Cytology of Primula Kewensis and other related Primula hybrids. Ann. Bot., vol. xxvi, 1912.

Ernst, A. : Bastardierung als Ursache der Apogamie im Pflanzenreich. Jena, 19 I 8.

Gates, R. R.: The Mutation Factor in Evolution with Particular Reference to Oenothera. London, I9I5.

Harrison and Doncaster: On Hybrids between Moths of the Sub-family Bistoninae, \&c. Journ. Gen., vol. iii, No. 4, 19I4.

Harrison, J. W. H. : Our British Roses, their Hybridology and other Genetical Problems. Trans. Nat. Hist. Soc. North. and Durham, 1920.

Holmgren, I.: Zytologische Studien über die Fortpflanzung bei den Gattungen Erigeron und Eupatorium. Kungl. Svenska Vet.-Akad. Handl., Bd. lix, No. 7, 19I9.

Juel, H. O.: Die Kernteilungen in den Pollenmutterzellen von Hemerocallis fulva und die bei denselben auftretenden Unregelmässigkeiten. Jahrb. f. wiss. Bot., Bd. xxx, 1897 . 1904 .

Lotsy, J. P. : Evolution by Means of Hybridization. The Hague, I9I6.

PACE, L. : Apogamy in Atamosco. Bot. Gaz., vol. lvi, IgI3.

Rosenberg, O.: Cytologische und morph. Studien an Drosera longifolia $\times$ D. rotundifolia. Kungl. Svenska Vet.-Akad. Handl., Bd, xliii, I909. 


\section{Rose Forms as determined by their Cytological Behaviour. 187}

Rosenberg, O.: Über die Chromosomenzahlen bei Taraxacum und Rosa. Svensk. Bot. Tidskr., Bd. iii, I909.

: Die Reduktionsteilung und ihre Degeneration in Hieracium. Ibid., Bd. xi, I917.

STtrasburger, E. : Die Apogamie der Eualchimillen und allgemeine Gesichtspunkte die sich aus ihr ergeben. Jahrb. wiss. Bot., I904.

TAHARA, M. : Cytological Studies on Chrysanthemum. II. Bot: Mag. (Tokio), I9I5.

Tä́ckholm, G. : On the Cytology of the Genus Rosa. A Preliminary Note. Svensk. Bot. Tidskr., Bd. xiv, I920.

Tischler, G. : Zellstudien an sterilen Bastardpflanzen. Archiv für Zellforsch., Bd. i, I908.

Winge, O.: Studier over Planterigets chromosomtal og chromosomernes betydning. Comptes rendus Lab. Carls., Copenhagen, I9I 7 .

Wolley-Dod, A. H. : A List of British Roses. London, I9II.

\section{EXPLANATION OF PLATES IX AND X.}

Illustrating Miss Blackburn and Dr. Harrison's paper on the Status of the British Rose Forms.

PIATE IX.

Illustrating Meiosis in the Pollen Development and the Somatic Mitoses in the Normal

Types of Rosa.

Figs. I-3, 7, I0-I 5 , and $18-22$ from Rosa arvensis.

Figs. 4-6, 8-9, 16, and 22-25 from Rosa pimpinellifolia, and Fig. I 7 from Rosa rugosa All the figures were drawn with the camera lucida. Mag. 4,000.

Fig. I. Pollen mother-cell previous to synapsis.

Fig. 2. Synapsis.

Fig. 3. Evolution of spireme from the synaptic knot.

Fig. 4. Spireme completely expanded.

Fig. 5. Bivalent units of spireme showing longitudinal split.

Fig. 6-9. Stages in development of the bivalents.

Fig. Io. Diakinesis.

Fig. I 1. Multipolar spindle stage.

Fig. I 2. Metaphase of the heterotype division.

Fig. 13. Equatorial plate of $R$. arvensis showing seven chromosomes.

Fig. I 4. Telophase.

Fig. I 5. Interkinesis after heterotype division.

Fig. I6. Metaphase of the homotype division.

Fig. I7. Anaphase from R. rugosa.

Fig. IS. Telophase of the homotype division.

Fig. I9. Completed tetrad.

Fig. 20. The four spores of the tetrad separated.

Fig. 21. Late somatic prophase.

Fig. 22. Somatic equatorial plate showing 14 chromosomes.

Fig. 23. The same in $R$. pimpinellifolia showing 28 chromosomes.

Fig. 24. Somatic metaphase.

Fig. 25. Late somatic anaphase.

Fig. 26. Synapsis in R. Sabini.

PLATE X.

Fig. 27. Spireme in R. Sabini.

Fig. 28. Differentiation of bivalent loops and univalent rods in $R$. parisiensis. 
Fig. 28 a. Slightly later stage from R. omissa.

Fig. 29. Diakinesis in $R$. Sabini, showing some bivalents.

Fig. 30. Bivalents on the spindle univalents still scattered from $R$. coriifolia.

Fig. 31. Complete metaphase in R. rubiginosa.

Fig. 32. Tripolar spindle in $R$. rubiginosa.

Fig. 33. Telophase of bivalents, anaphase of univalents, in R. Sabini.

Fig. 34. The same end on, showing the lateral position of the spindle in the mother-cell, Fig. 35. Slightly later stage in ( $K$. pimpinellifolia $\times$ coriifolia) $\times$ pimpinellifolia.

Fig. 36 . The same in $R$. coriifolia.

Fig. 37. Interkinesis in $R$. Sabini.

Fig. 38. Metaphase of the homotype division in K. Sabini.

Fig. 39. Anaphase of homotype in $R$. coriifolia.

Fig. 40. Curious double spindle from $R$. Sabini.

Fig. 4I. Interkinesis after the homotype showing numerous nuclei in $R$. coriifolia.

Fig. 42. Octad from $R$. rubiginosa.

Fig. 43. Young pollen grain from $R$. sylvestris showing three nuclei.

Fig. 44. Defective pollen grains with normal from R. flexibilis. $\times 250$.

Fig. 45. Somatic anaphase from $R$. sylvestris to show absolute regularity. 
Annals of Botany,

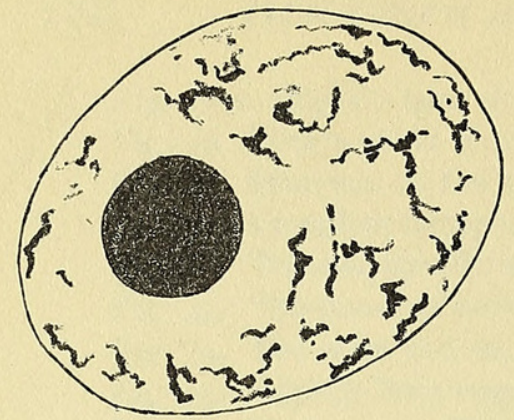

1.
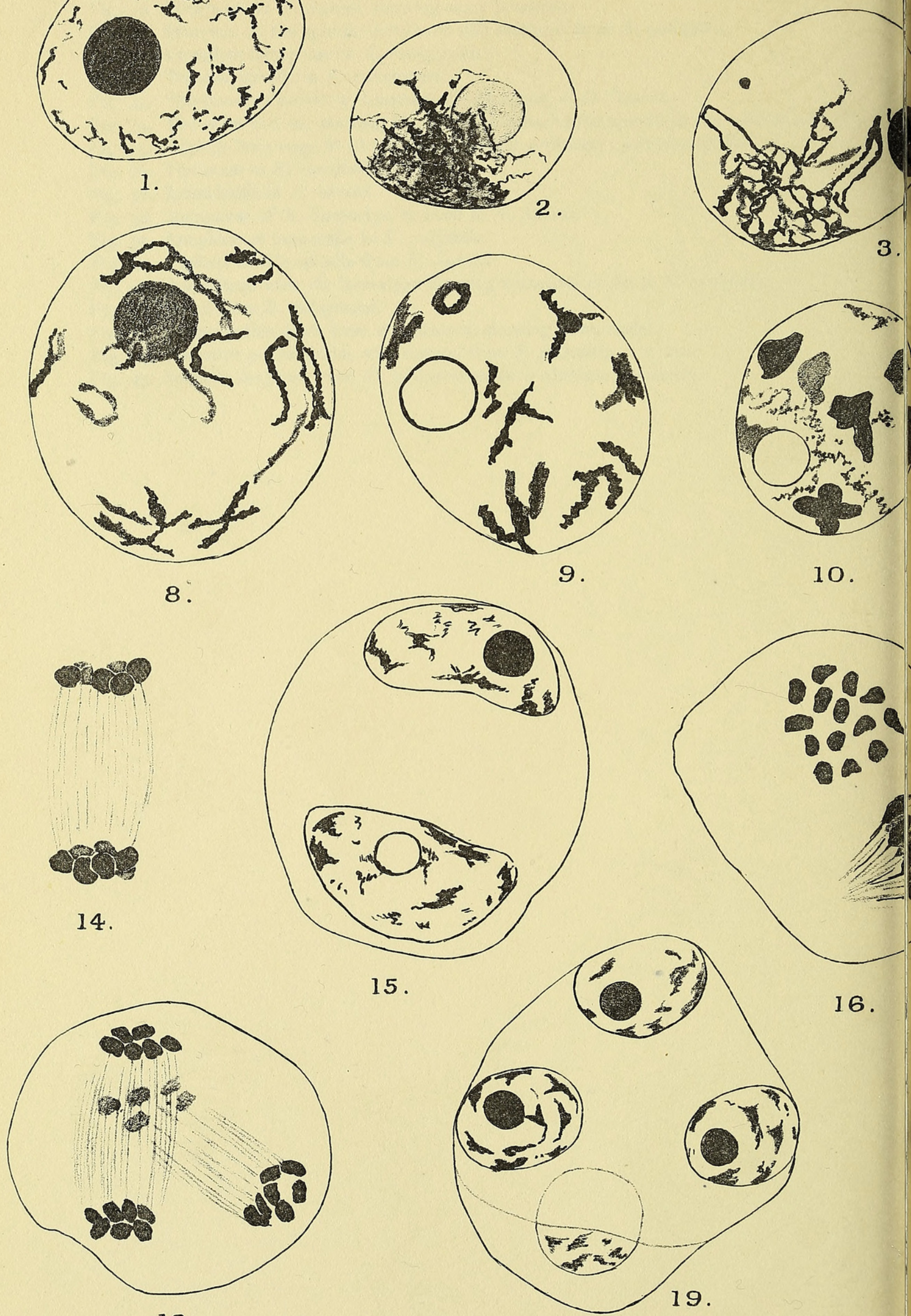

9.

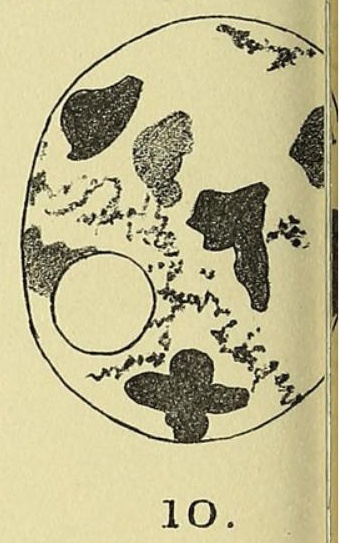

10.

18.

BLACKBURN \& HARRISON-ROSA. 
Vol. XXXV, Pl.IX.

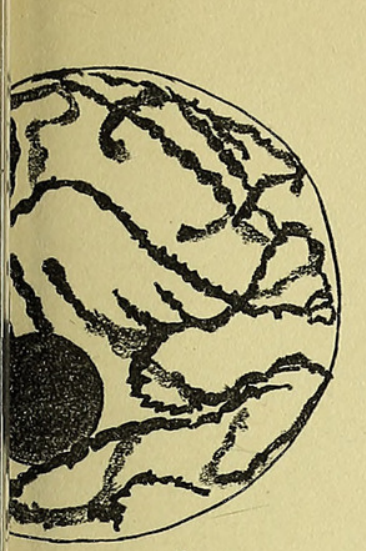

4.

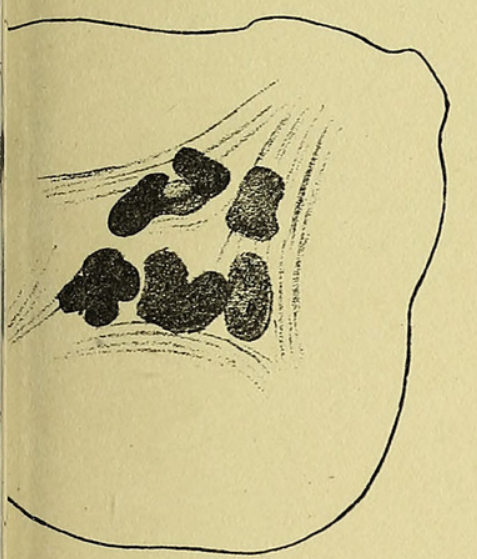

11.

60

17.

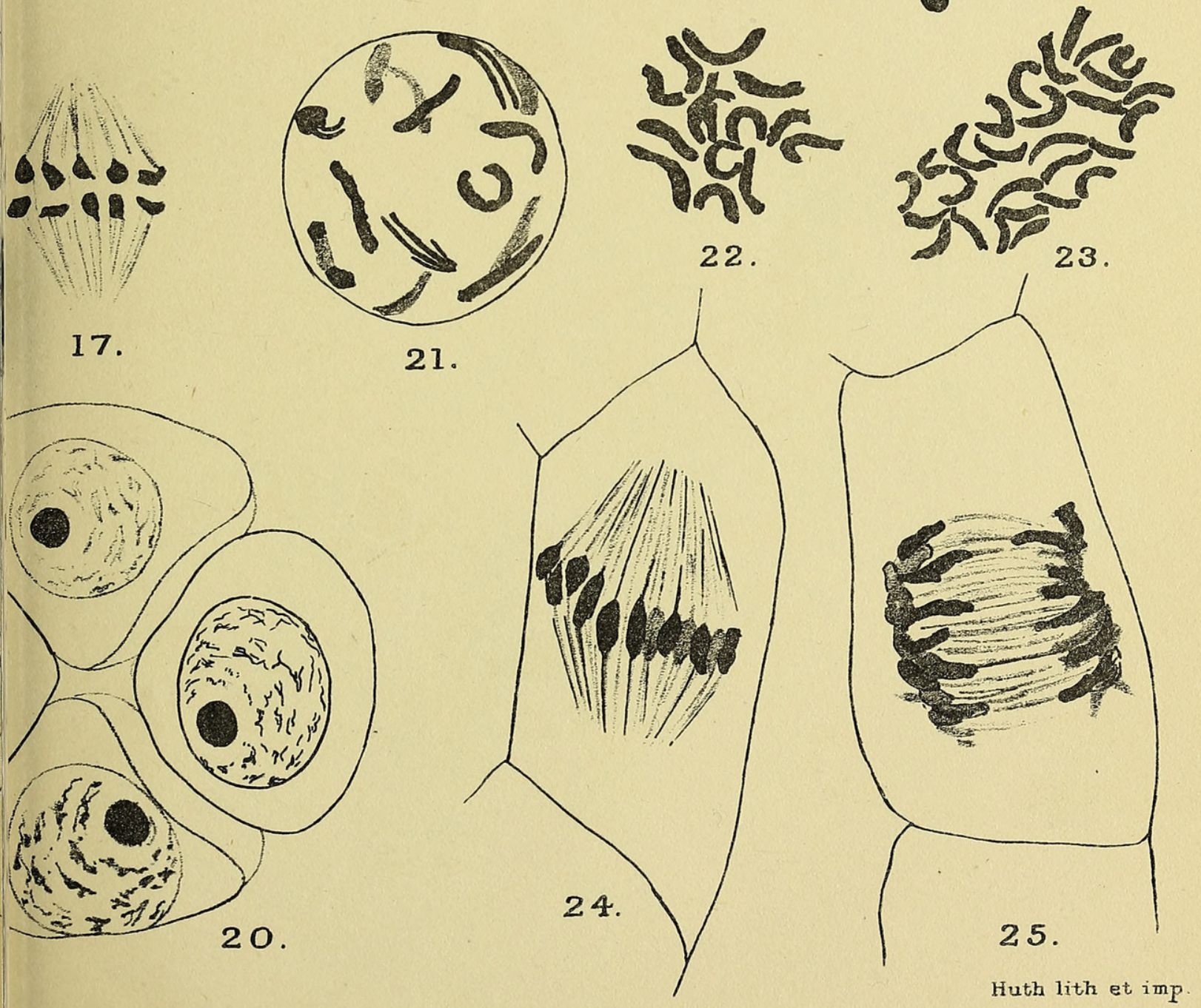

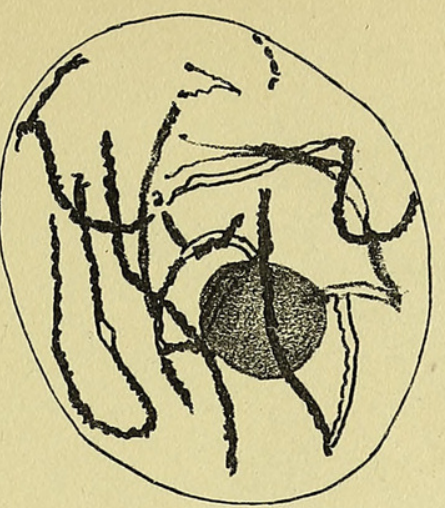

5.

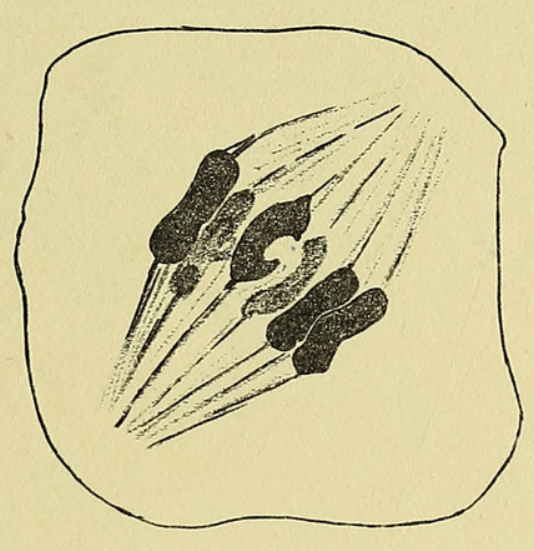

12.
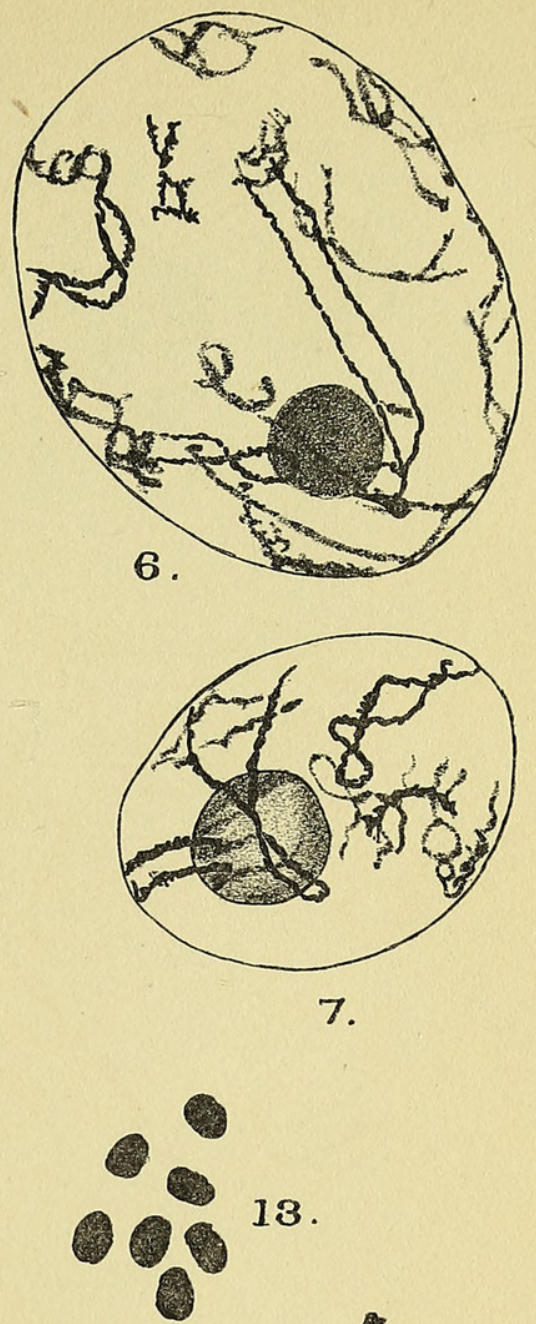
Annals of Botany,

Vol. XXXV, Pl.IX.
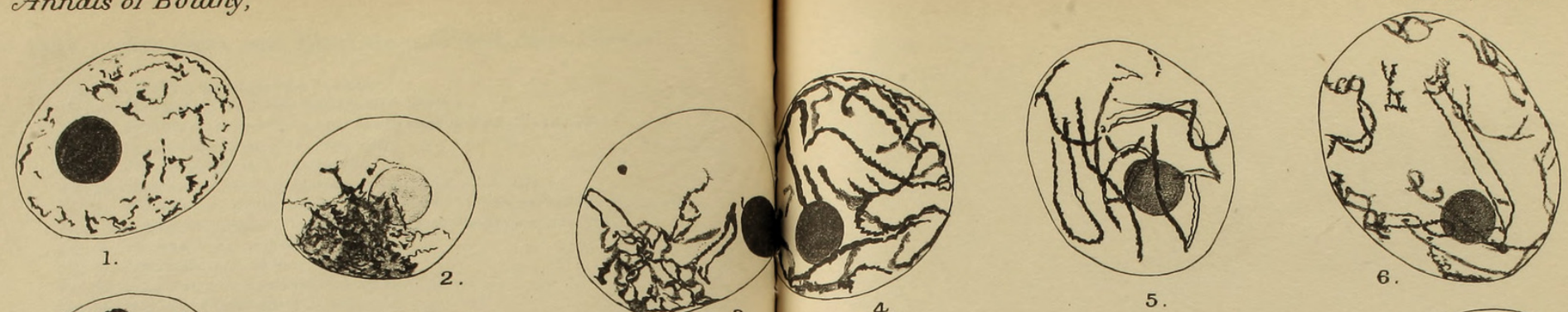

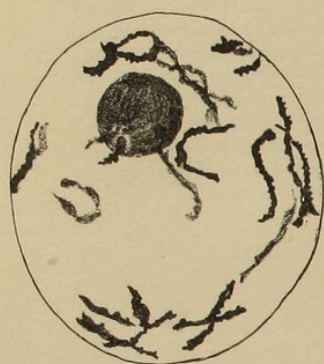
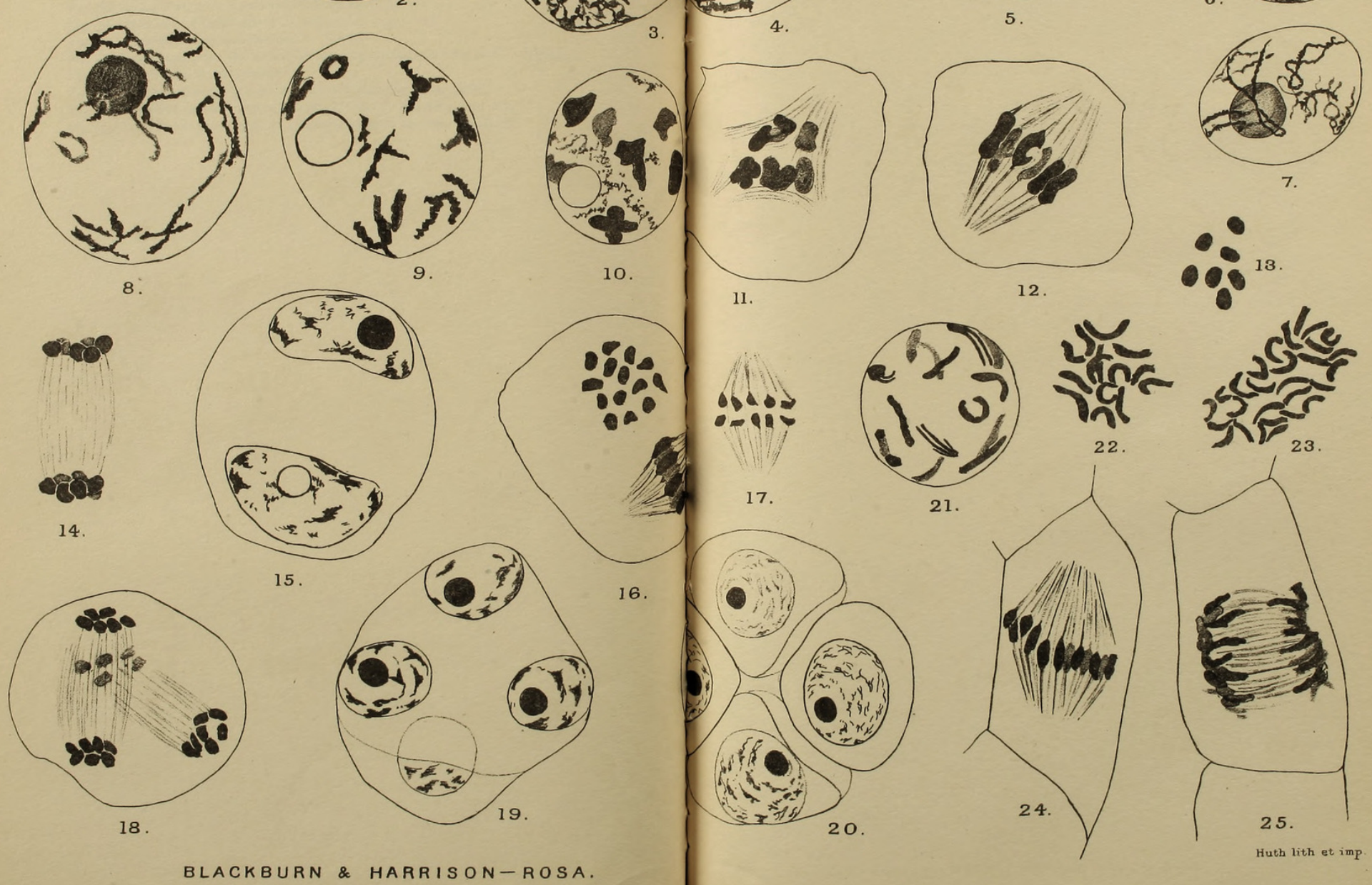
Annals of Botany,
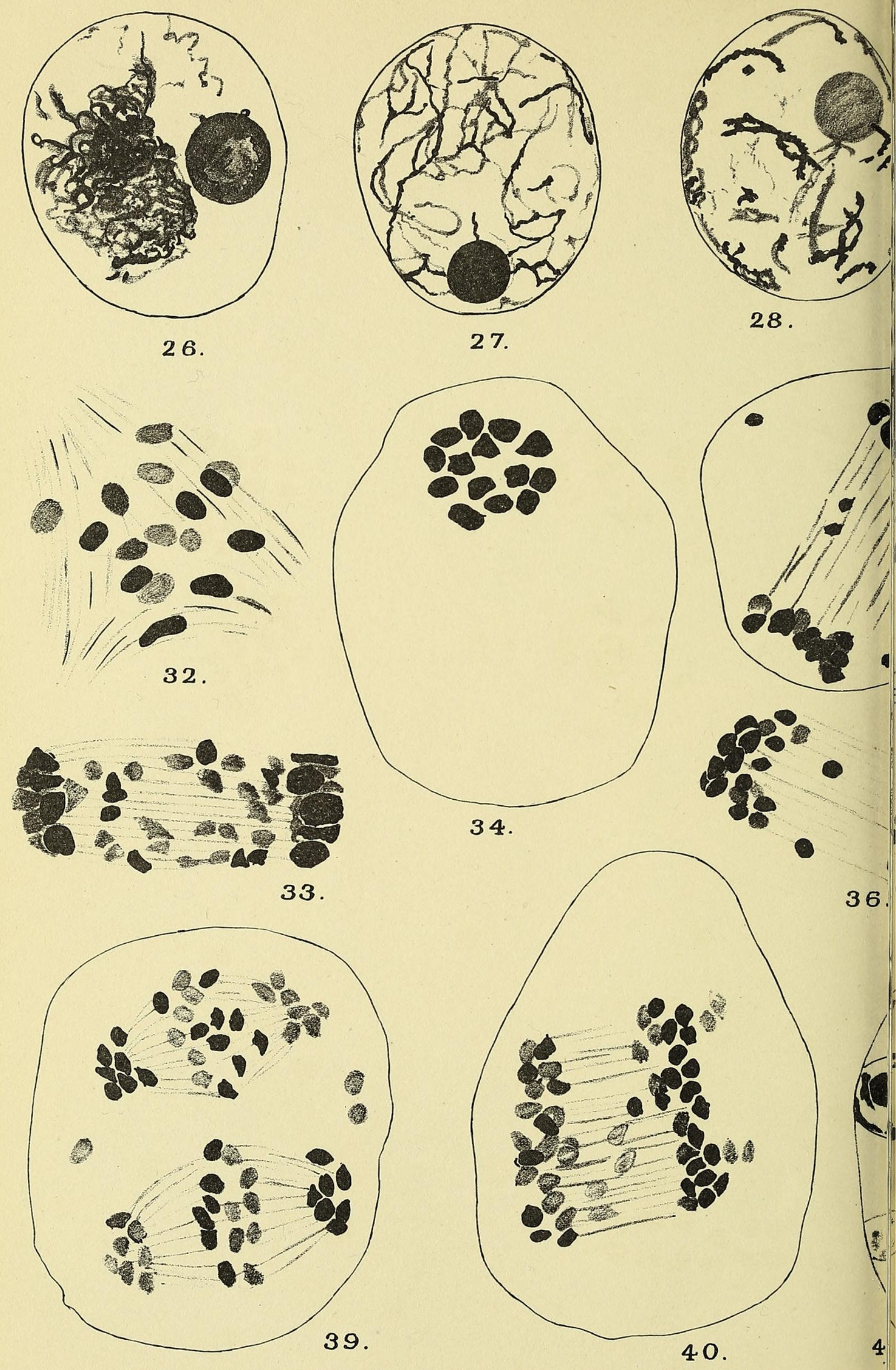

BLACKBURN \& HARRISON-ROSA. 


\section{$2 \mathrm{BHL}$ Biodiversity Heritage Library}

Blackburn, Kathleen B. and Harrison, J W Heslop. 1921. "The status of the British rose forms as determined by their cytological behaviour." Annals of botany 35, 159-188. https://doi.org/10.1093/oxfordjournals.aob.a089753.

View This Item Online: https://www.biodiversitylibrary.org/item/235780

DOI: https://doi.org/10.1093/oxfordjournals.aob.a089753

Permalink: https://www.biodiversitylibrary.org/partpdf/318998

\section{Holding Institution}

Smithsonian Libraries

\section{Sponsored by}

Biodiversity Heritage Library

\section{Copyright \& Reuse}

Copyright Status: Not in copyright. The BHL knows of no copyright restrictions on this item.

This document was created from content at the Biodiversity Heritage Library, the world's largest open access digital library for biodiversity literature and archives. Visit BHL at https://www.biodiversitylibrary.org. 